\title{
Ethyl acetate extract of germinated brown rice attenuates hydrogen peroxide-induced oxidative stress in human SH-SY5Y neuroblastoma cells: role of anti-apoptotic, pro-survival and antioxidant genes
}

Nur Hanisah Azmi ${ }^{1}$, Norsharina Ismail ${ }^{1}$, Mustapha Umar Imam $^{1}$ and Maznah Ismail ${ }^{1,2^{*}}$

\begin{abstract}
Background: There are reports of improved metabolic outcomes due to consumption of germinated brown rice (GBR). Many of the functional effects of GBR can be linked to its high amounts of antioxidants. Interestingly, dietary components with high antioxidants have shown promise in the prevention of neurodegenerative diseases like Alzheimer's disease (AD). This effect of dietary components is mostly based on their ability to prevent apoptosis, which is believed to link oxidative damage to pathological changes in AD. In view of the rich antioxidant content of GBR, we studied its potential to modulate processes leading up to AD.

Methods: The total phenolic content and antioxidant capacity of the ethyl acetate extract of GBR were compared to that of brown rice (BR), and the cytotoxicity of both extracts were determined on human SH-SY5Y neuronal cells using 3-(4,5-Dimethylthiazol-2-yl)-2,5-diphenyltetrazolium bromide (MTT) Assay. Based on its higher antioxidant potentials, the effect of the GBR extract on morphological changes due to hydrogen peroxide $\left(\mathrm{H}_{2} \mathrm{O}_{2}\right)$-induced oxidative damage in human SH-SY5Y neuronal cells was examined using inverted light microscope and fluorescence microscope by means of acridine orange-propidium iodide (AO/PI) staining. Also, evaluation of the transcriptional regulation of antioxidant and apoptotic genes was carried out using Multiplex Gene Expression System.
\end{abstract}

Results: The ethyl acetate extract of GBR had higher total phenolic content and antioxidant capacity compared to BR. The cytotoxicity results showed that GBR extract did not cause any damage to the human SH-SY5Y neuronal cells at concentrations of up to $20 \mathrm{ppm}$, and the morphological analyses showed that the GBR extract (up to $10 \mathrm{ppm}$ ) prevented $\mathrm{H}_{2} \mathrm{O}_{2}$-induced apoptotic changes in the cells. Furthermore, multiplex gene expression analyses showed that the protection of the cells by the GBR extract was linked to its ability to induce transcriptional changes in antioxidant (SOD 1, SOD 2 and catalase) and apoptotic (AKT, NF-KK, ERK1/2, JNK, p53 and p38 MAPK) genes that tended towards survival.

Conclusions: Taken together, the results of our study showed that the ethyl acetate extract of GBR, with high antioxidant potentials, could prevent $\mathrm{H}_{2} \mathrm{O}_{2}$-induced oxidative damage in $\mathrm{SH}-\mathrm{SY} 5 \mathrm{Y}$ cells. The potential of $\mathrm{GBR}$ and its neuroprotective mechanism in ameliorating oxidative stress-related cytotoxicity is therefore worth exploring further.

Keywords: Germinated brown rice, Antioxidant, Oxidative stress, Neuroprotective, SH-SY5Y

\footnotetext{
* Correspondence: maznah@medic.upm.edu.my

'Laboratory of Molecular Biomedicine, Institute of Bioscience, Universiti Putra Malaysia, 43400 UPM Serdang, Selangor, Malaysia

${ }^{2}$ Department of Nutrition and Dietetics, Universiti Putra Malaysia, 43400 UPM Serdang, Selangor, Malaysia
} 


\section{Background}

Oxidative stress and apoptosis underlie the pathogenesis of several neurodegenerative diseases including Alzheimer's disease $(\mathrm{AD})[1,2]$. Reactive oxygen species (ROS) produced in excess due to endogenous and/or exogenous stimuli would normally induce signal transduction that may result in mitochondrial dysfunction, cell death or cell survival [3]. The outcome of such insults on cells depends largely on the enormity of the insult and the ability of the cells to contain the insults or remove accumulating ROS. The brain cells are normally sensitive to the effects of ROS because they are a nidus for peroxidisable molecules, and because of their peculiar energetic demands [4]. In AD, ROS starts to accumulate in neurons before clinically evident signs and symptoms of the disease can be detected $[1,4]$. Studying mechanisms by which neurons cope with oxidative insults, therefore, serve as important avenues to evaluate potential preventive or therapeutic agents for $\mathrm{AD}$ development. When ROS accumulate, oxidative damage is normally prevented by induction of protective factors like antioxidants, which may not be effective if the insult is too overwhelming. In such cases, apoptotic mechanisms set in to remove neurons deemed unsalvageable $[1,5]$. Loss of neurons through these apoptotic deaths results in severe morphological and functional deficits, which manifest with progressive memory and cognitive decline.

Interestingly, the signal transduction mechanisms involved in neuronal survival or death are closely related. In fact, some shared mechanisms between the two extremes have been reported [3]. Specifically, the tumor suppressor gene p53 is reportedly activated by several oxidative insults including hydrogen peroxide $\left(\mathrm{H}_{2} \mathrm{O}_{2}\right)$. In response to its activation, other pathways are induced, mostly involving mitogen-activated protein kinases (MAPKs) like JNK and p38 [1]. The overall response of neurons to stimuli, however, depends on which pathways are predominantly regulated. For example, induction of the MAPKs (JNK and p38) is reportedly able to activate heme oxygenase-1 (HO-1), which counteracts the effects of ROS [6]. Also, induction of cyclo-oxygenase-II (COX-II) has been shown to ameliorate the harmful effects of ROS through its negative effects on p53 [7-9]. These complex interactions between pro-apoptotic and pro-survival pathways suggest that the neurons constantly work to prevent cell death and eventually morphological and functional defects on the brain except in extreme conditions, when they resort to apoptosis. The result of this damage is the development of senile plaques composed of primarily aggregated amyloid fibrils, and other pathological changes of $\mathrm{AD}$, which also propagate the disease [5]. However, endogenous production of antioxidant defenses like superoxide dismutases (SODs), activated by the presence of ROS, could initially boost the cells' ability to reduce ROS and remove the underlying stimuli [3]. This line of defense (antioxidants) can be potentiated through exogenous supplementation. Dietary antioxidants have been shown to block the pathways involved in apoptosis and eventual neuronal cell death, and hence their potential role in preventing or at least delaying the development of $\mathrm{AD}$ [10]. Curcumin, vitamins A, C and E, and flavonoids are notable examples of such antioxidants [10-12].

The promising role of antioxidants in preventing and/or delaying the development and progression of $\mathrm{AD}$ has generated interest in the search for other potent antioxidants with similar potential effects. Germinated brown rice (GBR) has been reported to have high antioxidant capacity [13]. It was also reported to improve antioxidant status in type 2 diabetes [14] and protect neuronal cells from oxidative stress-induced cytotoxicity [15,16]. This property of GBR is thought to be contributed by the potentiation of its bioactive compounds during the process of germination of brown rice (BR) [17]. Thus we studied the effects of a GBR extract on $\mathrm{H}_{2} \mathrm{O}_{2}$-induced oxidative stress in human SH-SY5Y neuronal cells and the transcriptional regulation of antioxidant and apoptotic genes. Human SH-SY5Y are derived from its parent SKN-SH neuroblastoma cells. Terminally differentiated human SH-SY5Y neuroblastoma cells are often used as an in vitro model to study neurodegenerative diseases because of their ability to respond in a similar manner to mature human neurons, when exposed to chemical agents in vitro $[18,19]$. We hypothesized that in view of GBR's higher content of antioxidant bioactives and better effects on oxidative stress than BR, its ethyl acetate extract could protect against $\mathrm{H}_{2} \mathrm{O}_{2}$-induced oxidative stress. Also, because apoptosis is important in oxidative stress-induced neurotoxicity, an understanding of its transcriptional regulatory mechanisms would provide a better insight into how GBR and its extracts exert their neuroprotective effects. This may broaden the understanding of the potential role of GBR in regulation of processes involved in neurodegenerative diseases and other closely related conditions.

\section{Methods}

\section{Materials}

All solvents were of analytical grade and were purchased from Merck (Darmstadt, Germany). Potassium persulphate $\left(\mathrm{K}_{2} \mathrm{~S}_{2} \mathrm{O}_{8}\right)$, sodium carbonate $\left(\mathrm{Na}_{2} \mathrm{CO}_{3}\right), 2$,2'-azino-bis[3ethylbenzothiazoline-6-sulphonic acid] (ABTS) reagent, di [phenyl]-[2,4,6-trinitrophenyl] iminoazanium (DPPH) reagent, Folin-Ciocalteu reagent, Trolox standard, gallic acid standard, Ham's nutrient mixture F-12, Minimum Essential Eagle's medium, fetal bovine serum, antibiotics and 3-(4,5-Dimethylthiazol-2-yl)-2,5-diphenyltetrazolium bromide (MTT) powder were purchased from SigmaAldrich (St. Louis, MO, USA). Other cell culture materials were purchased from BD Biosciences (NJ, USA). $\mathrm{H}_{2} \mathrm{O}_{2}$ 
and sodium hypochlorite $(\mathrm{NaOCl})$ were from Bendosen Laboratory Chemicals (Selangor, Malaysia) and from Dexchem Industries Sdn. Bhd. (Penang, Malaysia), respectively. The GenomeLab ${ }^{\mathrm{Tm}}$ GeXP Start Kit was purchased from Beckman Coulter Inc. (Miami, FL, USA), and the Total RNA Isolation kit was from RBC Bioscience Corp. (Taipei, Taiwan). Magnesium chloride $\left(\mathrm{MgCl}_{2}\right)$ and DNA Taq polymerase were purchased from Thermo Fisher Scientific (Pittsburgh, PA, USA).

\section{Germination of brown rice and preparation of extract} PadiBerasNasional (BERNAS) factory, Sri Tiram Jaya, Selangor provided the BR of Malaysian variety (MR219 and MR220) used in this study. BR was germinated as reported in an earlier publication [14]. Briefly, BR was soaked in $0.1 \% \mathrm{NaOCl}(1: 5, \mathrm{w} / \mathrm{v})$ and $0.5 \% \mathrm{H}_{2} \mathrm{O}_{2}(1: 5$, $\mathrm{w} / \mathrm{v}$ ) for $30 \mathrm{~min}$ and $6 \mathrm{~h}$ respectively, and incubated at $37^{\circ} \mathrm{C}$ for $18 \mathrm{~h}$. Germination was shown by sprouting, and the final moisture content was $8-11 \%$ after drying at $50^{\circ} \mathrm{C}$.

GBR and BR were dried and ground using a grinder. Extraction of GBR and BR were respectively carried out using ethyl acetate. Briefly, $5 \mathrm{~g}$ of GBR and BR powders were dissolved in $20 \mathrm{~mL}$ of ethyl acetate. The mixtures were sonicated for $1 \mathrm{~h}$. The extracts were then filtered through Whatman filter paper No. 1 and the entire extraction process was repeated twice on the residue obtained from the filtration process. The filtrates were pooled and solvent was removed from the filtrates under reduced pressure (Rotavapor R210, Buchi, Postfach, Flawil, Switzerland). Finally, the extracts were cooled in a desiccator and kept at $-80^{\circ} \mathrm{C}$ until further analyses.

\section{DPPH free radical and ABTS radical cation scavenging assays}

The abilities of GBR and BR extracts to scavenge DPPH free radical were determined according to the method described by Chan et al., 2012 [20]. Briefly, $4.2 \mathrm{mg}$ of DPPH powder was dissolved in $50 \mathrm{~mL}$ of $100 \%$ methanol $(0.2 \mathrm{mM})$. A Trolox stock solution was prepared as a standard. GBR and BR extracts were reacted with $195 \mu \mathrm{L}$ of $\mathrm{DPPH}$ methanolic solution in 96-well microtitre plates. After 60 minutes of incubation, the absorbance values of the samples were read at $540 \mathrm{~nm}$ using a microplate reader (Opsys $\mathrm{MR}^{\mathrm{TM}}$ 96well microplate reader, Dynex Technologies, VA, USA). DPPH scavenging activities of the extracts/Trolox standard were calculated using the following equation:-
ABTS radical scavenging activities of the extracts were determined according to the method reported by Kim et al., 2010 [21]. Briefly, $6.62 \mathrm{mg}$ of $\mathrm{K}_{2} \mathrm{~S}_{2} \mathrm{O}_{8}$ was dissolved in $10 \mathrm{~mL}$ of distilled water to prepare a solution of $2.45 \mathrm{mM}$.Then, $7 \mathrm{mM}$ ABTS was prepared by dissolving $38.4 \mathrm{mg}$ in $10 \mathrm{~mL}$ distilled water. The two solutions were mixed and incubated in the dark for $16 \mathrm{~h}$ prior to use. The mixture was diluted with distilled water until a spectrophotometric absorbance of $0.700 \pm 0.005$ at $735 \mathrm{~nm}$ was obtained. Next, $100 \mu \mathrm{L}$ of samples/Trolox standard were reacted with $900 \mu \mathrm{L}$ of the diluted ABTS solution and vortexed. The absorbance was read at $734 \mathrm{~nm}$. ABTS radical cation scavenging activity was calculated as the percentage reduction in absorbance.

\section{Total Phenolic content analysis}

Total phenolic contents (TPCs) of GBR and BR extracts were determined using Folin-Ciocalteu method. Briefly, $10 \mathrm{mg}$ of the extracts were dissolved in $1 \mathrm{~mL}$ of methanol. The solutions $(0.1 \mathrm{~mL})$ were individually mixed with $2.5 \mathrm{~mL}$ of 10 -fold diluted Folin-Ciocalteau reagent, and $2.0 \mathrm{~mL}$ of $7.5 \% \mathrm{Na}_{2} \mathrm{CO}_{3}$. After incubation at $40^{\circ} \mathrm{C}$ for $60 \mathrm{~min}$, the absorbance of the reaction mixture was measured at $760 \mathrm{~nm}$ using a spectrophotometer (Pharmaspec UV-1700, Shimadzu, Kyoto, Japan). Gallic acid was used as a standard and TPC of the extract was expressed in $\mathrm{mg}$ gallic acid equivalents (mg GAE/g extract).

\section{Cell culture}

The human neuroblastoma SH-SY5Y cells were grown in complete culture medium containing mixture (1:1) of Minimum essential Eagle's medium and Ham's nutrient mixture F-12, which was supplemented with $10 \%$ fetal bovine serum, 1\% MEM non-essential amino acids and $50 \mu \mathrm{g} / \mathrm{mL}$ gentamicin. Cells were maintained at $37^{\circ} \mathrm{C}$ under $5 \% \mathrm{CO}_{2}$ and $95 \%$ air. Dimethyl sulfoxide (DMSO) concentration was maintained at $0.1 \%$ for all cell culture assays.

\section{MTT assay}

The abilities of GBR and BR to protect SH-SY5Y cells from $\mathrm{H}_{2} \mathrm{O}_{2}$ were determined by MTT assay, which is a potential indicator of cell viability. SH-SY5Y cells were seeded into 96-well culture plates at a density of $2 \times 10^{5}$ cells $/ \mathrm{mL}$ and were allowed to attach. After 2 days, cells were differentiated with retinoic acid $(10 \mu \mathrm{M})$ for 6 days prior to treatment. To examine the possible toxic effects, the cells were treated with GBR and BR over a

$$
\text { DPPH Scavenging Activity }=\frac{A b s_{\text {negative control }}-A b s_{\text {extract } / \text { standard }}}{A b s_{\text {negative control }}} \times 100 \%
$$


concentration range of $1-30 \mathrm{ppm}$ for $24 \mathrm{~h}$. For the determination of neuroprotective effects, cells were pretreated with the respective extracts diluted in serumfree medium for $24 \mathrm{~h}$ and then challenged with $250 \mu \mathrm{M}$ $\mathrm{H}_{2} \mathrm{O}_{2}$, which is the $\mathrm{IC}_{50}$ of $\mathrm{H}_{2} \mathrm{O}_{2}$ [15], for another $1 \mathrm{~h}$. MTT was added to all the wells and allowed to incubate in the dark at $37^{\circ} \mathrm{C}$ for $4 \mathrm{~h}$. The amount of MTT formazan product was determined by measuring absorbance at 540 $\mathrm{nm}$ using a Microplate reader (Opsys MR, Thermo Labsystems, Franklin, MA, USA). All the MTT assays were performed in triplicate.

\section{Morphological analysis using inverted light microscope}

SH-SY5Y cells were seeded into 6-well culture plates at a density of $2 \times 10^{5}$ cells $/ \mathrm{mL}$ and were allowed to attach. After 2 days, cells were differentiated with retinoic acid $(10 \mu \mathrm{M})$ for 6 days prior to treatment. Cells were treated with GBR at concentrations of 1 and $10 \mathrm{ppm}$ for $24 \mathrm{~h}$ before exposing them to $250 \mu \mathrm{M} \mathrm{H}_{2} \mathrm{O}_{2}$ for another $1 \mathrm{~h}$. After the incubation period, cultures were observed under phase contrast, using a $40 \times$ objective in an inverted microscope (Nikon ECLIPSE TS100, Nikon Corporation, Tokyo, Japan) and then photographed using a digital camera (Nikon DS-Fi1, Nikon Corporation, Tokyo, Japan) and the image acquisition software NIS Elements D 3.0 version. Multiple independent images were taken.

\section{Acridine orange and propidium iodide (AO/PI) staining using fluorescence microscope}

SH-SY5Y cells were seeded, treated with GBR and $250 \mu \mathrm{M} \mathrm{H} \mathrm{H}_{2} \mathrm{O}_{2}$ as previously described. After the incubation period, the growth medium was discarded. Cells were then stained with the dye mixture $(10 \mu \mathrm{L}$ of $1 \mathrm{mg} / \mathrm{mL}$ $\mathrm{AO}$ and $10 \mu \mathrm{L}$ of $1 \mathrm{mg} / \mathrm{mL} \mathrm{PI})$. Stained cells were examined using an inverted fluorescence microscope (Olympus, Tokyo, Japan). Multiple independent images were taken.

\section{Multiplex gene expression analysis RNA extraction}

At the end of the experiment, SH-SY5Y cells treated with GBR extract were washed with phosphate-buffered saline (PBS), and RNA isolated using Total RNA Isolation kit (RBC Bioscience Corp., Taiwan) according to the manufacturer's protocol. RNA concentration was determined using NanoDrop spectrophotometer (Thermo Scientific Nanodrop, NanoDrop Technologies, Wilmington, DE, USA). The ratios of A260/230 and A260/280 were used to indicate the purity of extracted total RNA.

\section{Primer design}

Primers were designed on the GenomeLabeXpress Profiler software using Homo sapien sequence adopted from the National Center for Biotechnology Information GenBank Database [22]. The genes of interest, housekeeping genes and internal control are shown on Table 1. The forward and reverse primers had universal tag sequences in addition to nucleotides that were complementary to the target genes. Primers were supplied by First Base Ltd. (Selangor, Malaysia), and diluted in $1 \mathrm{X}$ TE Buffer to a concentration of $500 \mathrm{nM}$ for reverse primers and $200 \mathrm{nM}$ for forward primers.

\section{Reverse transcription and polymerase chain reaction (PCR)}

Reverse transcription (RT) and multiplex PCR of RNA samples $(50 \mathrm{ng} / \mu \mathrm{L})$ were carried out in XP Thermal Cycler (BIOER Technology, Hangzhou, China) according to GenomeLab ${ }^{\text {тs }}$ GeXP Start Kit (Beckman Coulter, Inc, Miami, FL, USA). Briefly, RT reaction mixture was prepared using RNA sample (1 $\mu \mathrm{L}$ each), $4 \mu \mathrm{L}$ of $5 \mathrm{X}$ RT Buffer, $2 \mu \mathrm{L}$ of RT Reverse Primers, $1 \mu \mathrm{L}$ of KanR, $1 \mu \mathrm{L}$ of Reverse Transcriptase and $11 \mu \mathrm{L}$ of DNAse/RNase free water. cDNA was synthesized according to the reaction protocol: $48^{\circ} \mathrm{C}$ for $1 \mathrm{~min}, 42^{\circ} \mathrm{C}$ for $60 \mathrm{~min}, 95^{\circ} \mathrm{C}$ for $5 \mathrm{~min}$ and $4^{\circ} \mathrm{C}$ hold. Also, $9.3 \mu \mathrm{L}$ of each cDNA was mixed with $10.7 \mu \mathrm{L}$ of PCR reaction mixture consisting of 5X PCR Buffer, $25 \mathrm{mM} \mathrm{MgCl}_{2}$, PCR Forward Primer Plex, and Thermo-Start DNA polymerase. Amplification conditions were $95^{\circ} \mathrm{C}$ for $10 \mathrm{~min}$, followed by 34 cycles of $94^{\circ} \mathrm{C}$ for $30 \mathrm{sec}, 55^{\circ} \mathrm{C}$ for $30 \mathrm{sec}, 70^{\circ} \mathrm{C}$ for $1 \mathrm{~min}$ and $4^{\circ} \mathrm{C}$ hold.

\section{GEXP data analysis}

PCR products ( $1 \mu \mathrm{L}$ each) from the above reactions were mixed with $38.5 \mu \mathrm{L}$ of sample loading solution and $0.5 \mu \mathrm{L}$ of DNA size standard 400 (Beckman Coulter, Inc, Miami, FL, USA) in a 96-well sample loading plate and analyzed on the GeXP machine (Beckman Coulter, Inc, Miami, FL, USA). The results from the machine were analyzed using the Fragment Analysis module of the GeXP system software and then imported onto the analysis module of eXpress Profiler software. Normalization was performed with 18 sRNA according to manufacturer's instructions.

\section{Statistical analysis}

All data are presented as mean \pm SD. The data was evaluated by one-way ANOVA using Statistical Package for Social Sciences software, version 20 (SPSS Inc., Chicago, IL). Differences between the means were assessed using Tukey's multiple comparisons and Student's $t$-test. Statistical significance was considered at $p<0.05$.

\section{Results and discussion}

\section{DPPH free radical and $A B T S$ radical cation scavenging} activities and TPCs of GBR and BR

As can be recalled, GBR has higher antioxidant capacity than BR, due to its higher bioactive compounds including antioxidants [17]. As shown on Table 2, the antioxidant 
Table 1 Gene name, accession number, reverse and forward primer sequences used in GeXP multiplex gene expression analysis

\begin{tabular}{|c|c|c|c|}
\hline \multirow[t]{2}{*}{ Gene name } & \multirow{2}{*}{$\begin{array}{l}\text { Accession } \\
\text { number }\end{array}$} & \multicolumn{2}{|l|}{ Primer sequences* with universal tags (underlined) } \\
\hline & & Forward & Reverse \\
\hline$\overline{\text { GAPDH }^{a}}$ & NM_002046 & AGGTGACACTATAGAATAAAGGTGAAGGTCGGAGTCAA & $\begin{array}{l}\text { GTACGACTCACTATAGGGAGATCTCGCTCCTGGAAGATG } \\
\end{array}$ \\
\hline $\operatorname{KanR}^{\mathrm{b}}$ & - & AGGTGACACTATAGAATAATCATCAGCATTGCATTCGATTCCTGTTTG & GTACGACTCACTATAGGGAATTCCGACTCGTCCAACATC \\
\hline Hyaluronidase ${ }^{a}$ & AJ000099 & AGGTGACACTATAGAATACAGCAGTTCATGCTGGAGAC & GTACGACTCACTATAGGGACCAGGTAGACAGACGGGAAG \\
\hline 18 sRNA ${ }^{\mathrm{a}, \#}$ & M10098 & AGGTGACACTATAGAATAGGAGTGGAGCCTGCGGCTTAA & GTACGACTCACTATAGGGATAGCATGCCAGAGTCTCGTT \\
\hline $\mathrm{ACTB}^{\mathrm{a}}$ & NM_001101 & AGGTGACACTATAGAATAGATCATTGCTCCTCCTGAGC & GTACGACTCACTATAGGGAAAAGCCATGCCAATCTCATC \\
\hline AKT & NM_001014431 & $\underline{\text { AGGTGACACTATAGAATAGAGGAGATGGACTTCCGGTC }}$ & GTACGACTCACTATAGGGAAGGATCTTCATGGCGTAGTAGC \\
\hline p53 & NM_001126117 & AGGTGACACTATAGAATAGGGGAGCAGGGCTCA & GTACGACTCACTATAGGGAAAAATGGCAGGGGAGGG \\
\hline JNK & NM_139046 & $\underline{\text { AGGTGACACTATAGAATACAGAAGCTCCACCACCAAAGAT }}$ & GTACGACTCACTATAGGGAGCCATTGATCACTGCTGCAC \\
\hline ERK1/2 & NM_002745 & 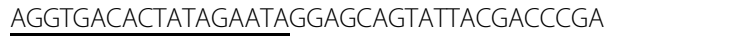 & GTACGACTCACTATAGGGAGATGTCTGAGCACGTCCAGT \\
\hline p38 MAPK & NM_001315 & $\underline{\text { AGGTGACACTATAGAATATTCAGTCTITGACTCAGATGCC }}$ & GTACGACTCACTATAGGGAGTCAGGCTTTTCCACTCATCT \\
\hline SOD 1 & NM_000454 & AGGTGACACTATAGAATATCATCAATTTCGAGCAGAAGG & GTACGACTCACTATAGGGA TGCTTITCATGGACCACC \\
\hline SOD 2 & NM_000636 & AGGTGACACTATAGAATACATCAAACGTGACTTTGGTTC & GTACGACTCACTATAGGGACTCAGCATAACGATCGTGGTT \\
\hline Catalase & NM_001752 & $\underline{\text { AGGTGACACTATAGAATAGAAGTGCGGAGATTCAACACT }}$ & $\underline{\text { GTACGACTCACTATAGGGA ACACGGATGAACGCTAAGCT }}$ \\
\hline
\end{tabular}


capacities of the ethyl acetate extracts used in this study suggest that GBR may have superior functional effects than BR. In addition, the TPCs of GBR and BR extracts were calculated using the linear standard curve, $\mathrm{y}=$ $0.0144 x+0.0267\left(R^{2}=0.9991\right)$, and were found to be $17.01 \pm 1.27$ and $10.81+0.24 \mathrm{mg} \mathrm{GAE} / \mathrm{g}$ extract, respectively. These findings corroborate earlier reports on antioxidant capacities of GBR [23]. The role of antioxidants in prevention of apoptosis and other mechanisms that promote AD development is well established [10-12]. Through direct scavenging and/or activation of prosurvival mechanisms, antioxidants could prevent or at least delay the development of $\mathrm{AD}$. The bioactive compounds responsible for the functional effects of GBR are still the subject of debate. However, multiple bioactive compounds may be responsible for any given effects due to GBR. We have reported a higher antioxidant capacity for methanolic extract of GBR compared to BR [13], while in two other studies we have demonstrated that the ethanolic extracts of GBR possessed higher antioxidant capacities $[14,15]$. These data indicate the abundance of antioxidants in GBR due to potentiation of bioactive compounds during germination. In view of the reports on anti-apoptotic effects of dietary components with high antioxidant potentials in $\mathrm{AD}$, we hypothesized that our GBR type could regulate apoptosis and potentially prevent neuronal death.

\section{MTT assay}

To determine the effect of our antioxidant-rich extract on the viability of SH-SY5Y cells, we treated the cells with concentrations between 1-30 ppm. As reported in our earlier publication [15], we determined the $\mathrm{IC}_{50}$ of $\mathrm{H}_{2} \mathrm{O}_{2}$ to be $250 \mu \mathrm{M}$, hence it was used to challenge the cells after treatment with the ethyl acetate extracts. $\mathrm{H}_{2} \mathrm{O}_{2}$ is believed to induce intracellular defense mechanisms that tend towards production of more endogenous antioxidant, but when overwhelming, it leads to apoptosis and cell death [1]. In the presence of an exogenous antioxidant, the endogenous antioxidants get support in ameliorating the $\mathrm{H}_{2} \mathrm{O}_{2}$-induced oxidative damage $[3,4]$. As shown on Figure 1, concentrations of between 1 and
$15 \mathrm{ppm}$ of the ethyl acetate extract of GBR improved cell viability better than those of BR, likely due to its higher amounts of antioxidants. This is supported by earlier findings that dietary components with higher antioxidant capacities will promote neuronal cell survival [12]. However, the figure shows that at concentrations between 15 and $30 \mathrm{ppm}$ of the GBR extract, cell viability reduced drastically compared to BR. This may have been due to suppression of endogenous antioxidant and other defenses that leave neurones vulnerable to more injury leading to a hormetic response. Under normal conditions, oxidative insults induce stress proteins and endogenous antioxidants that try to neutralize the stimuli. The presence of exogenous antioxidants potentiates these responses but when in excess, they could have a negative effect on endogenous cellular stress response, thereby increasing the sensitivity of the cells to stimuli and easily leading to cell death [24]. For our subsequent experiments, therefore, 1 and $10 \mathrm{ppm}$ were used.

\section{Morphological analysis using inverted light microscope}

Morphology of untreated and treated SH-SY5Y cells was observed under light microscope, to evaluate apoptotic features of the cells. From Figure 2, it can be seen that untreated control cells showed normal appearance of SH-SY5Y, which were elongated and flattened with axon-like outgrowths, while the $\mathrm{H}_{2} \mathrm{O}_{2}$-treated cells were shrunken, rounded, shiny and condensed, and showed surface blebs and disruption of the neurites [25]. The morphological analysis of the cells treated with the GBR extract showed that the $\mathrm{H}_{2} \mathrm{O}_{2}$-induced apoptotic changes were not present. This shows that the GBR extract effectively protected the cells from the oxidative damage caused by $\mathrm{H}_{2} \mathrm{O}_{2}$.

\section{Acridine orange (AO)/ propidium iodide $(\mathrm{PI})$ staining}

Fluorescent microscopy was carried out to observe any morphological changes and apoptotic features of normal untreated and treated SH-SY5Y cells by means of AO and PI staining. AO is membrane-permeable and stains the cell nuclei green, indicating the cells are viable. On the other hand, the intercalating dye PI is membrane-

Table 2 DPPH and ABTS antioxidant assays and total phenolic content for germinated brown rice (GBR) in comparison to brown rice (BR)

\begin{tabular}{lccc}
\hline Extract & $\begin{array}{c}\text { DPPH free radical } \\
\text { scavenging assay }{ }^{*,+}\end{array}$ & $\begin{array}{c}\text { ABTS scavenging activity } \\
\text { (mg TEAC/g extract) }^{*}\end{array}$ & $\begin{array}{c}\text { Total phenolic content } \\
\text { (mg GAE/g extract) }^{\#}\end{array}$ \\
\hline GBR & $2.32+0.04^{* *}$ & $23.89+0.24^{* *}$ & $17.01+1.27^{* *}$ \\
BR & $10.37 \pm 0.47$ & $3.59 \pm 0.09$ & $10.81+0.24$ \\
\hline
\end{tabular}

"Expressed as $\mathrm{IC}_{50}(\mathrm{mg} / \mathrm{ml})$, calculated from Trolox standard curve $\left(\mathrm{y}=0.0087 \mathrm{x}+4.587, \mathrm{r}^{2}=0.9957\right)$, with smaller values signifying higher antioxidant capacity. \#Values expressed as mean \pm standard deviation. ${ }^{* *}$ Indicates statistical significance at $p<0.05$ compared to BR for each assay represented in a column. ABTS, 2,2'-azino-bis[3-ethylbenzothiazoline-6-sulphonic acid]; DPPH, di[phenyl]-[2,4,6-trinitrophenyl]iminoazanium. 


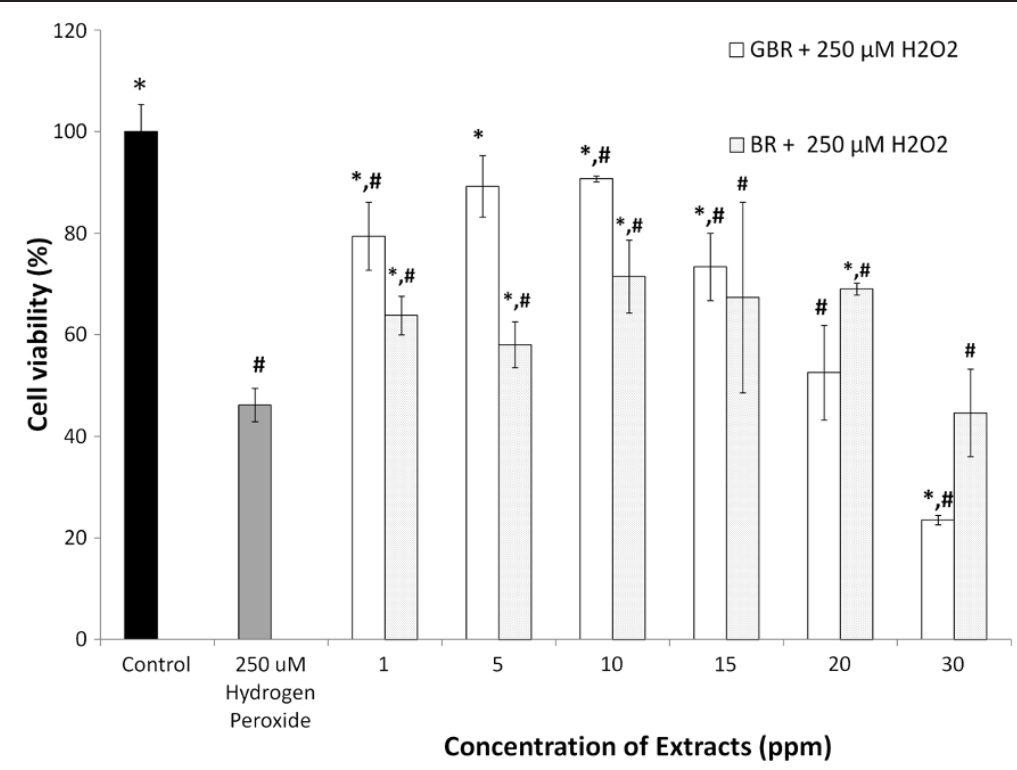

Figure 1 Cell viabilities of SH-SY5Y cells after pretreatment with ethyl acetate extracts of germinated brown rice (GBR) and brown rice (BR), followed by hydrogen peroxide $\left(\mathrm{H}_{2} \mathrm{O}_{2}\right)$; Cells were pretreated with $\mathrm{GBR}$ and $\mathrm{BR}$ extracts individually over concentration of 1-30

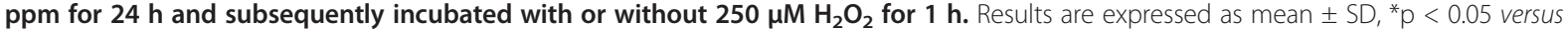
$\mathrm{H}_{2} \mathrm{O}_{2}$. \# $\mathrm{p}<0.05$ versus control.

impermeable, thus only taken up by non-intact cells and stains the nuclei red. As shown in Figure 3, the nuclei of untreated normal cells are stained green and showed normal structure, while $\mathrm{H}_{2} \mathrm{O}_{2}$-treated cells are stained red and orange, representing the hallmark of apoptosis. As for the GBR-treated cells, majority of the cells were stained green, showing normal appearance of intact cells.
Effects of ethyl acetate extract of GBR on mRNA levels of antioxidant genes

The mRNA levels of three antioxidant genes (catalase, SOD 1 and SOD 2) and six apoptotic/oxidative stressrelated genes were studied using Multiplex GeXP genetic analysis system, with KanR as the internal control. The complete list of target and housekeeping genes is shown


Figure 2 Light micrographs of human SH-SY5Y cells. Bar $=50 \mu \mathrm{M}$. SH-SY5Y cells viewed under light microscope, $40 \mathrm{X}$ magnification; (a) Untreated control cells. (b) Treatment with $250 \mu \mathrm{M} \mathrm{H}_{2} \mathrm{O}_{2}$ for 1 h. (c) Cells pretreated with 1 ppm of GBR extract and subsequent treatment with $250 \mu \mathrm{M} \mathrm{H}_{2} \mathrm{O}_{2}$ for $1 \mathrm{~h}$. (d) Cells pretreated with $10 \mathrm{ppm}$ of GBR extract and subsequent treatment with $250 \mu \mathrm{M} \mathrm{H} \mathrm{H}_{2}$ for $1 \mathrm{~h}$. 

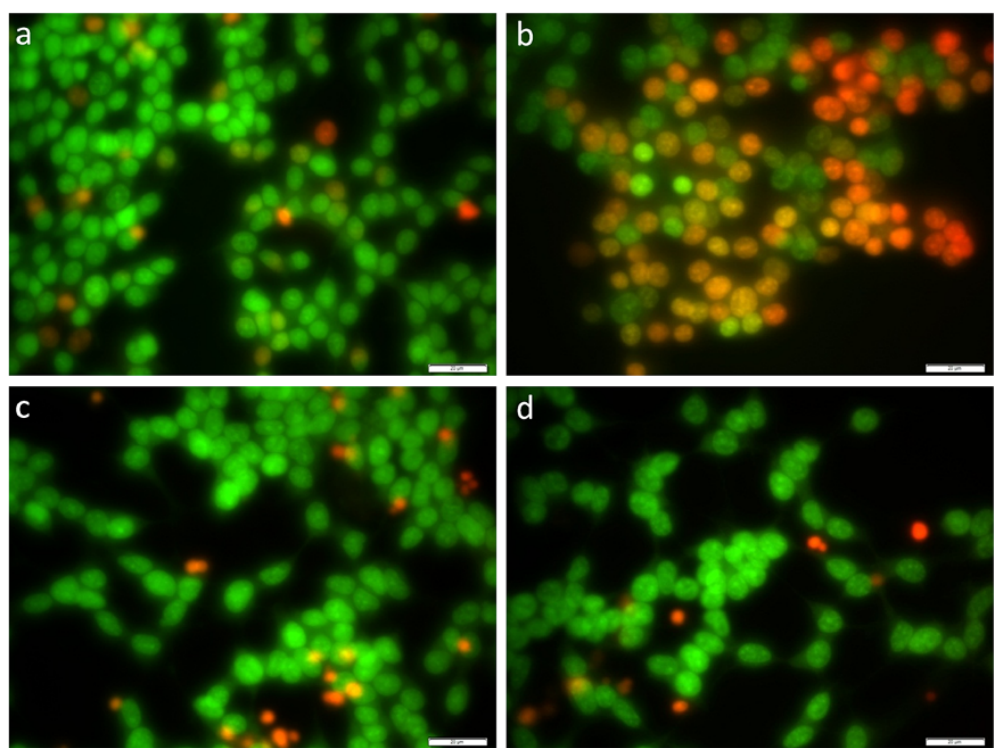

Figure 3 Fluorescent micrographs of acridine orange (AO, green) and propidium iodide ( $\mathrm{PI}$, red) double-stained human SH-SY5Y cells viewed under fluorescence microscope. Bar $=20 \mu \mathrm{M}$; (a) Untreated control cells. (b) Treatment with $250 \mu \mathrm{M} \mathrm{H} \mathrm{H}_{2}$ for 1 h. (c) Cells pretreated with $1 \mathrm{ppm}$ of GBR extract and subsequent treatment with $250 \mu \mathrm{M} \mathrm{H}_{2} \mathrm{O}_{2}$ for 1 h. (d) Cells pretreated with $10 \mathrm{ppm}$ of GBR extract and subsequent treatment with $250 \mathrm{\mu M} \mathrm{H}_{2} \mathrm{O}_{2}$ for $1 \mathrm{~h}$.

on Table 1. As shown in Figure 4, the treatment with $250 \mu \mathrm{M} \mathrm{H}_{2} \mathrm{O}_{2}$ upregulated the mRNA levels of all antioxidants, although only SOD 2 was significantly higher than that of untreated cells. The treatments with GBR extract at concentrations of 1 and $10 \mathrm{ppm}$, followed by subsequent treatment with $250 \mu \mathrm{M} \mathrm{H} \mathrm{H}_{2} \mathrm{O}_{2}$ upregulated the expression of the three antioxidant genes in comparison to $\mathrm{H}_{2} \mathrm{O}_{2}$-treated controls and normal untreated cells. In the case of SOD 1, the GBR extract upregulated the gene significantly higher than untreated controls in a dose-dependent manner, but did not show significantly different expression levels in comparison to $\mathrm{H}_{2} \mathrm{O}_{2}$ treated controls. The mRNA levels of SOD 2 were also higher in the GBR-treated cells compared to normal untreated cells and $\mathrm{H}_{2} \mathrm{O}_{2}$-treated controls, although there was no significant difference between $\mathrm{H}_{2} \mathrm{O}_{2}$-treated and GBR-treated cells. The mRNA levels of catalase were similar to SOD 1, in which the expression due to GBR treatment was found to be higher than in normal untreated cells but not significantly higher than in $\mathrm{H}_{2} \mathrm{O}_{2}$ treated cells.

The expression patterns of the antioxidant genes due to $\mathrm{H}_{2} \mathrm{O}_{2}$ treatment is in agreement with findings that $\mathrm{H}_{2} \mathrm{O}_{2}$ normally induces antioxidant defenses, especially SODs, in cells [1]. The upregulation of antioxidant defenses is an attempt to boost endogenous antioxidants to prevent oxidative damage on cells $[3,4]$. In addition, exogenous antioxidants may potentiate the expression of the antioxidant genes as seen in Figure 4. The implication of the GBR treatments is that the potentiation of the antioxidant gene expression by the GBR extracts would confer more protection to the cells. This upregulation of antioxidant genes is similar to what we have reported previously in diabetic rats due to consumption of GBR [14], and in Hep-G2 cells due to different extracts of GBR [26].

Effects of ethyl acetate extract of GBR on mRNA levels of p53 and MAP kinases (JNK, ERK1/2 and p38), AKT and nuclear factor kappa $\beta$ (NF-K $\beta$ )

$\mathrm{H}_{2} \mathrm{O}_{2}$ is known to induce oxidative damage to neuronal cells through induction of apoptotic mechanisms. These involve activation of transcriptional factors and signal transducers like p53 and MAPKs [1]. In the current study, we evaluated the possible apoptotic mechanisms modulated by the ethyl acetate extract of GBR in improving neuronal cell survival. Figure 5 shows the effects of the GBR extract on p53, MAPKs, AKT and NF-K $\beta$. $\mathrm{H}_{2} \mathrm{O}_{2}$ significantly upregulated p53, p38 and JNK, while it downregulated ERK1/2, AKT and NF-K $\beta$, compared to untreated controls. These factors may all mediate cell survival or death [3], and it appears that their patterns of expression tended towards activation of apoptotic mechanisms $[1,4]$. Upregulation of p53, p38 and JNK are normal responses to ROS, although they could also mediate protective mechanisms. However, it is the downregulation of ERK1/2, AKT and NF-K $\beta$ that suggest likely activation of a death signal, because their upregulation have all been linked to cell survival through activation of COX-II [1,27]. Their downregulation by $\mathrm{H}_{2} \mathrm{O}_{2}$ in the current study suggests that neuronal cells 


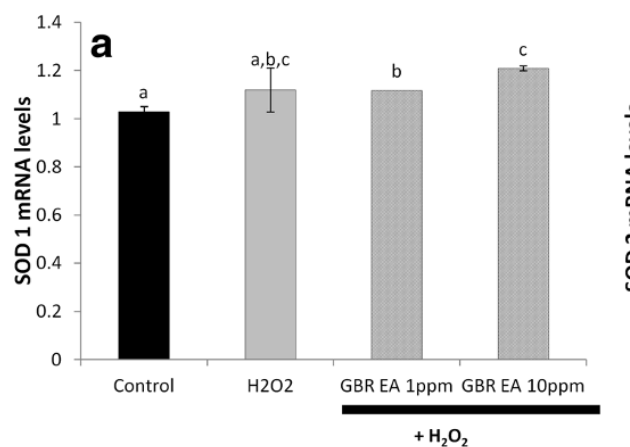

$+\mathrm{H}_{2} \mathrm{O}_{2}$
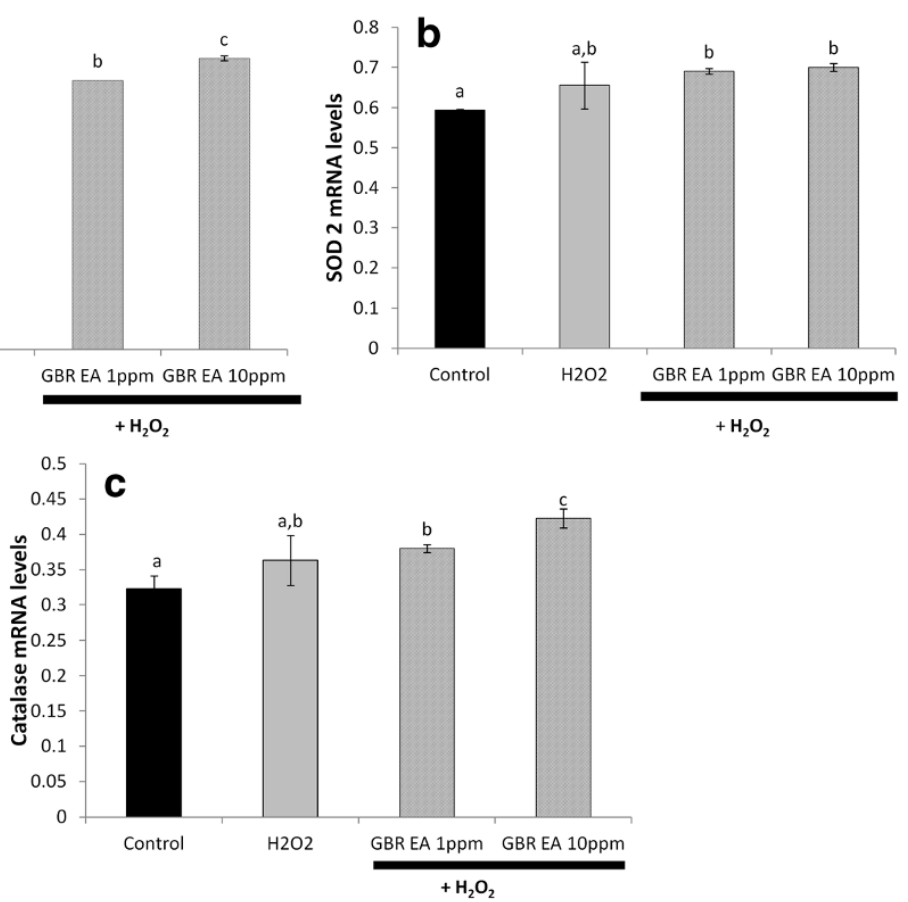

Figure 4 Expression levels of the superoxide dismutase (SOD) 1, SOD 2 and catalase genes in SH-SY5Y cells. mRNA levels of (a) the SOD 1, (b) the SOD 2, and (c) the catalase genes following treatment with 1 and 10 ppm of GBR extract and subsequent treatment with $250 \mu M$ $\mathrm{H}_{2} \mathrm{O}_{2}$, in comparison to untreated and $250 \mu \mathrm{M} \mathrm{H}_{2} \mathrm{O}_{2}$-treated controls. Bars represent means of groups $(n=3)$ and error bars represent SDs. Different letters on any 2 bars representing each gene indicate statistically significant difference $(p<0.05)$ between the groups.

treated with $\mathrm{H}_{2} \mathrm{O}_{2}$ alone were inclined towards apoptosis rather than cell survival.

Treatment with GBR extract (1 and $10 \mathrm{ppm}$ ) prior to the $\mathrm{H}_{2} \mathrm{O}_{2}$ insult showed signs of anti-apoptosis towards the SH-SY5Y cells by upregulating the expression of AKT, NF-K $\beta$ as well as ERK1/2. Additionally, the GBR treatment resulted in suppression of the p53, p38 and JNK compared to the $\mathrm{H}_{2} \mathrm{O}_{2}$-treated control. The effects of different doses of GBR extract (1 and 10 ppm) on p38 MAPK and JNK gene expressions were found to be in a dose-dependent manner as well, in which higher concentration showed higher suppression of the genes. Likewise, the treatment of GBR extract at $1 \mathrm{ppm}$ also significantly lowered the expression of p53 gene. However, the expression of the gene following treatment with $10 \mathrm{ppm}$ of the extract appeared to have slightly increased, but not significantly different from untreated control. Increase in mRNA levels of $A K T, N F-K \beta$ and ERK1/2, and decrease in those of JNK, p38 and p53 suggest that the GBR extract may have anti-apoptotic and pro-survival effects on neuronal cells. Activation of COX-II by AKT and NF-K $\beta$ is known to have a negative effect on the transcriptional level and activity of p53, which could eventually lead to lower transcription of JNK and p38, since p53 modulates the activities of the latter two [1,27]. In fact, upregulation of the AKT gene has been shown to be a very important mechanism in regulating p53-induced apoptosis [28], signifying its importance in the prevention of apoptosis in the current study.

Transcriptional regulation of genes that regulate apoptosis like JNK and NF-K $\beta$ are mechanisms by which dietary components have been shown to modulate the apoptosis and survival of neuronal cells and eventually the risk of AD [11]. Neuronal death due to oxidative stress mediated by apoptosis largely contributes to the pathological changes and eventual symptomatology of $\mathrm{AD}$ and other neurodegenerative diseases. The abilities of dietary components to potentially prevent or at least retard the progression of these diseases have been linked to their abilities to prevent neuronal death and enhance cell survival through prevention of apoptosis. In this regard, dietary components, like flavonoids and curcumin, with high antioxidant capacities have shown promise, leading to hypotheses of the importance of foods with high antioxidant composition in the prevention of apoptosis and neuronal cell death in neurodegenerative diseases like $\mathrm{AD}[11,12]$. In the current study, we have been able to demonstrate that the ethyl acetate extract of GBR has high antioxidant capacity and also possesses anti-apoptotic and pro-survival properties in neuronal cells. 


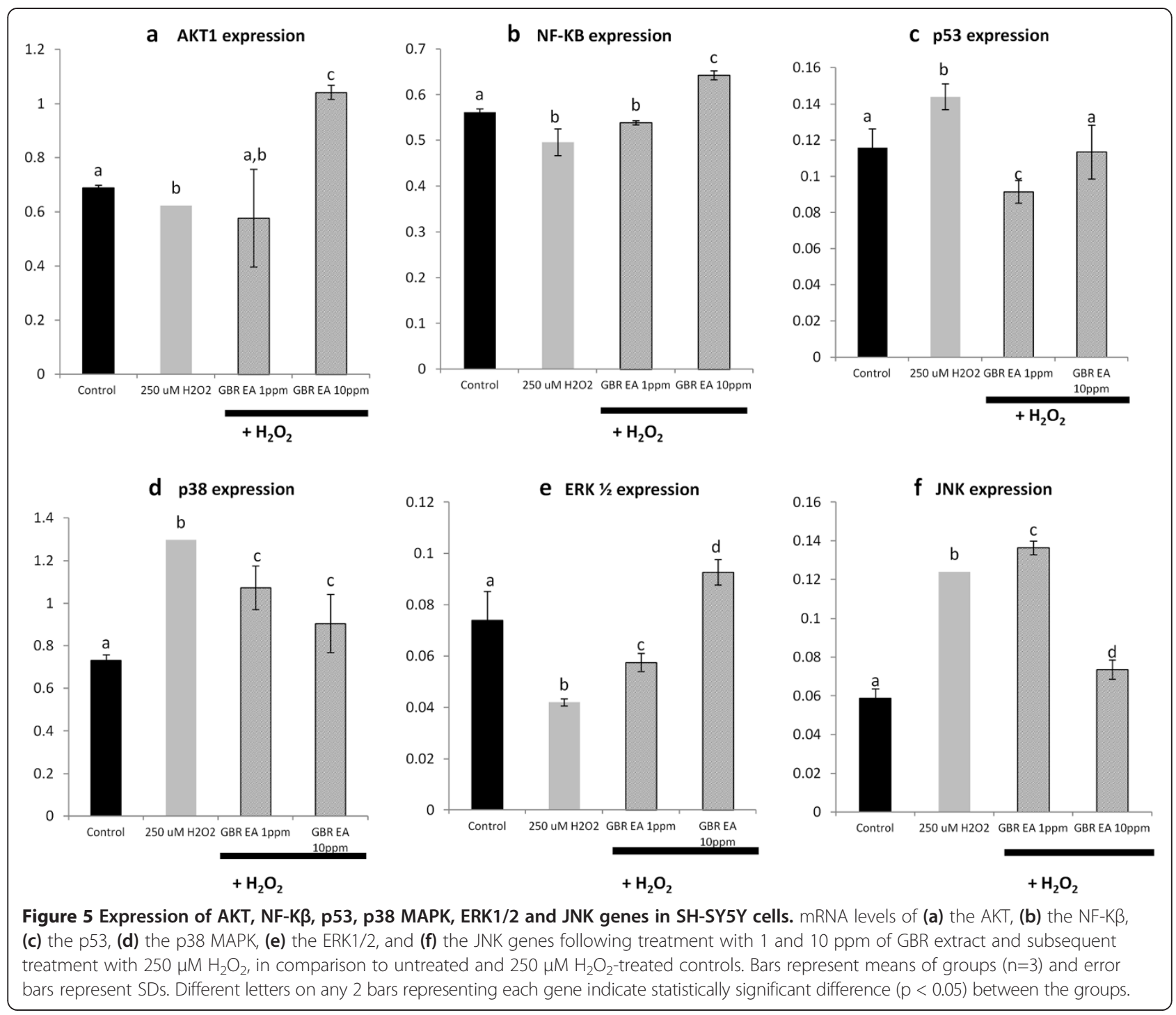

\section{Conclusions}

Germination of BR is known to improve its bioactive compounds and several studies have reported enhanced functional effects of GBR over BR. Also, GBR has been shown to possess high antioxidant capacity, as we have demonstrated in the current study. Interestingly, oxidative damage on neurons is mediated mostly through apoptosis, and dietary components with high antioxidant capacities have been shown to prevent or at least delay the processes leading up to neurodegeneration. In the current study, we showed that the ethyl acetate extract of GBR increased cell viability in the presence of $\mathrm{H}_{2} \mathrm{O}_{2}$. The increase in cell viability was likely mediated through anti-apoptotic effects of the extract as demonstrated by the morphological changes under microscope and changes in transcriptional regulation of genes that tended more towards survival and less towards apoptosis. Taken together, it could be argued that GBR may reduce oxidative stress-induced neurotoxicity due to its high antioxidant potentials and ability to promote neuronal cell survival in the presence of $\mathrm{H}_{2} \mathrm{O}_{2}$-induced oxidative stress, since oxidative stress is an important contributor to neurodegenerative diseases. Our findings are therefore worth studying further, in order to provide more insight into the protective effects of GBR and its bioactives against neurodegenerative disease processes like $\mathrm{AD}$, and especially what regulatory pathways they modulate.

\section{Abbreviations}

AD: Alzheimer's disease; ABTS: 2,2'-azino-bis[3-ethylbenzothiazoline-6sulphonic acid]; DPPH: Di[phenyl]-[2,4,6-trinitrophenyl]iminoazanium; GAE: Gallic acid equivalents; $\mathrm{H}_{2} \mathrm{O}_{2}$ : Hydrogen peroxide; MTT: 3-(4,5Dimethylthiazol-2-yl)-2,5-diphenyltetrazolium bromide; DMSO: Dimethyl sulfoxide; GBR: Germinated brown rice; BR: Brown rice; NF-Kß: Nuclear factor-kappa $\beta$; PBS: Phosphate buffered saline; ROS: Reactive oxygen species; TEAC: Trolox Equivalents; MAPK: Mitogen-activated protein kinase; JNK: Jun N-terminal kinase; ERK: Extracellular signal related kinases;

COX: Cyclooxygenase; GAPDH: Glyceraldehyde 3-phosphate dehydrogenase. 


\section{Competing interests}

The authors declare that they have no competing interests.

\section{Authors' contributions}

NHA designed the study and carried out the experimental parts. MUI critically read and revised the manuscript. $\mathrm{NI}$ and $\mathrm{Ml}$ supervised the work and experimental designs, and approved the final manuscript for submission. All authors read and approved the final manuscript.

\section{Acknowledgements}

This work was supported by Padiberas National Berhad (BERNAS, Malaysia). The authors also wish to thank Mr. Mohd Khairil Othman from Matrix Optics (M) Sdn. Bhd. for the technical assistance in fluorescence microscopy analysis and all staff of Laboratory of Molecular Biomedicine for the help during the study.

Received: 21 February 2013 Accepted: 30 May 2013

Published: 17 July 2013

\section{References}

1. Klein JA, Ackerman SL: Oxidative stress, cell cycle, and neurodegeneration. J Clin Invest 2003, 111(6):785-793. Review.

2. Kannan K, Jain SK: Oxidative stress and apoptosis. Pathophysiology 2000 7(3):153-163. Review.

3. Martindale $\mathrm{J}$, Holbrook NJ: Cellular response to oxidative stress: signaling for suicide and survival. J Cell Physiol 2002, 192(1):1-15. Review.

4. Gandhi S, Abramov AY: Mechanism of oxidative stress in neurodegeneration. Oxid Med Cell Longev 2012, 2012:11 pages. Article ID 428010

5. Moreira PI, Nunomura A, Honda K, Aliev G, Casadenus G, Zhu X, Smith MA Perry G: The key role of oxidative stress in Alzheimer's disease. Oxidative Stress and Neurodegenerative Disorders 2007:451-466. "The Key Role of Oxidative Stress in Alzheimer's Disease," in Oxidative Stress and Neurodegenerative Disorders, 1 ed., G. A. Q. a. S. H. Parvez, Ed., Elsevier, 2007, pp. 267-281.

6. Aggeli IKS, Gaitanaki C, Beis I: Involvement of JNKs and p38-MAPK/MSK1 pathways in $\mathrm{H} 2 \mathrm{O} 2$-induced upregulation of heme oxygenase-1 mRNA in H9c2 cells. Cell Signal 2006, 18(10):1801-1812.

7. Luo J, Nikolaev AY, Imai S, Chen D, Su F, Shiloh A, Guarente L, Gu W: Negative control of p53 by Sir2a promotes cell survival under stress. Cell 2001, 107(2):137-148.

8. Choi EM, Heo Jl, Oh JY, Kim YM, Ha KS, Kim Jl, Han JA: COX-2 regulates p53 activity and inhibits DNA damage-induced apoptosis. Biochem Biophys Res Commun 2005, 328(4):1107-1112.

9. Han JA, Kim Jl, Ongusaha PP, Hwang DH, Ballou LR, Mahale A, Aaronson SA, Lee SW: P53-mediated induction of Cox-2 counteracts p53- or genotoxic stress-induced apoptosis. EMBO J 2002, 21(21):5635-5644.

10. Ferrari CKB: Diet, herbs, and nutritional protection against oxidative stress in neurological diseases. In Oxidative Stress and Neurodegenerative Disorders. Edited by Qureshi GA, Parvez SH. Amsterdam: Elsevier Science B.V; 2007:525-541.

11. Di Matteo V, Pierucci M, Di Giovanni G, Esposito E: Prevention and therapy of neurodegenerative disorders: role of nutritional antioxidants. In Oxidative Stress and Neurodegenerative Disorders. Edited by Qureshi GA Parvez SH. Amsterdam: Elsevier Science B.V; 2007:621-661.

12. Butterfield D, Castegna A, Pocernich C, Drake J, Scapagnini G, Calabrese V: Nutritional approaches to combat oxidative stress in Alzheimer's disease. J Nutr Biochem 2002, 13(8):444-461. Review.

13. Sani IM, Iqbal S, Chan KW, Ismail M: Effect of acid and base catalyzed hydrolysis on the yield of phenolics and antioxidant activity of extracts from germinated brown rice (GBR). Molecules 2012, 17(6):7584-7594.

14. Imam MU, Musa SNA, Azmi NH, Ismail M: Effects of white rice, brown rice and germinated rrown rice on antioxidant status of type 2 diabetic rats. Int J Mol Sci 2012, 13(10):12952-12969.

15. Ismail N, Ismail M, Fathy SF, Musa ASN, Imam MU, Foo JB, lqbal S: Neuroprotective effects of germinated brown rice against hydrogen peroxide induced cell death in human SH-SY5Y cells. Int J Mol Sci 2012, 13(8):9692-9708

16. Soi-ampornkul R, Junnu S, Kanyok S, Liammongkolkul S, Katanyoo W, Umpornsirirat S: Antioxidative and neuroprotective activities of the pregerminated brown rice extract. Food Nutr Sci 2012, 3(1):135-140.
17. Patil SB, Khan MK: Germinated brown rice as a value added rice product: A review. J Food Sci Technol 2011, 48(6):661-667.

18. Encinas M, Iglesias M, Liu Y, Wang H, Muhaisen A, Cena V, Gallego C, Comella JX: Sequential treatment of SH-SY5Y cells with retinoic acid and brain-derived neurotrophic factor gives rise to fully differentiated, neurotrophic factor-dependent, human neuron-like cells. J Neurochem 2000, 75:991-1003.

19. Myers TA, Nickerson CA, Kaushal D, Ott CM, Honer zu Bentrup K, Ramamurthy R, Nelman-Gonzalez M, Pierson DL, Philipp MT: Closing the phenotypic gap between transformed neuronal cell lines in culture and untransformed neurons. J Neurosci Methods 2008, 174:31-41.

20. Chan KW, Khong NM, Iqbal S, Ismail M: Simulated gastrointestinal pH condition improves antioxidant properties of wheat and rice flours. Int Mol Sci 2012, 13(6):7496-7507.

21. Kim H, Moon JY, Kim H, Lee DS, Cho M, Choi HK, Kim YS, Mosaddik A Cho SK: Antioxidant and antiproliferative activities of mango (<i>Mangiferaindica</i> L.) flesh and peel. Food Chem 2010, 121(2):429-436.

22. National Center for Biotechnology Information GenBank Database: 2012. [Available: http://www.ncbi.nlm.nih.gov/nucleotide/], (accessed 15 March 2012).

23. Imam MU, Azmi NH, Bhanger MI, Ismail N, Ismail M: Antidiabetic properties of germinated brown rice: a systematic review. Evid Based Complement Alternat Med 2012:12 pages.

24. Ristow M, Zarse K: How increased oxidative stress promotes longevity and metabolic health: the concept of mitochondrial hormesis (mitohormesis). Exp Gerontol 2010, 45(6):410-418. Review.

25. Fitzgerald JC, Ufer C, Billett EE: A link between monoamine oxidase-A and apoptosis in serum deprived human SH-SY5Y neuroblastoma cells. J Neural Transm 2007, 114(6):807-810.

26. Imam MU, Ismail M, Omar AR: Nutrigenomic effects of germinated brown rice bioactives on antioxidant genes. Free Radic Biol Med 2012, 53:S105-S106

27. Crossthwaite AJ, Hasan S, Williams RJ: Hydrogen peroxide-mediated phosphorylation of ERK1/2, Akt/PKB and JNK in cortical neurones: dependence on $\mathrm{Ca}(2+)$ and PI3-kinase. J Neurochem 2002, 80(1):24-35.

28. Gottlieb TM, Leal JF, Seger R, Taya Y, Oren M: Cross-talk between Akt, p53 and Mdm2: possible implications for the regulation of apoptosis. Oncogene 2002, 21(8):1299-1303.

doi:10.1186/1472-6882-13-177

Cite this article as: Azmi et al:: Ethyl acetate extract of germinated brown rice attenuates hydrogen peroxide-induced oxidative stress in human SH-SY5Y neuroblastoma cells: role of anti-apoptotic, pro-survival and antioxidant genes. BMC Complementary and Alternative Medicine $201313: 177$

\section{Submit your next manuscript to BioMed Central and take full advantage of:}

- Convenient online submission

- Thorough peer review

- No space constraints or color figure charges

- Immediate publication on acceptance

- Inclusion in PubMed, CAS, Scopus and Google Scholar

- Research which is freely available for redistribution 